\title{
The Retinal Vasculature of the Chinese Hamster: A Preliminary Study
}

\author{
J.L. Federman and G.C. Gerritsen
}

The Department of Ophthalmology, Jefferson Medical College of Thomas Jefferson University, Philadelphia, Pennsylvania, and the Upjohn Company, Kalamazoo, Michigan, USA

Summary. Various clinical and histologic approaches to the study of the retinal vasculature of the chinese hamster are described. The techniques include fundus photography, fluorescein angiography and the labeling of possibly damaged capillaries with carbon particles. A small group of untreated juvenile diabetic and control chinese hamsters were investigated. Histologic study showed evidence suggestive of pathology at the capillary level in the diabetics. The endothelial cell (E) to intramural pericyte (IMP) ratio was significantly elevated in the diabetic animals.

Etudes préliminaires des vaisseaux rétiniens du hamster chinois

Résumé. Différentes approches cliniques et histologiques sont décrites pour l'étude du système vasculaire rétinien des hamsters chinois. Ces méthodes comportent l'examen photographique du fond de l'oeil, l'angiographie à la fluorescéine et le marquage des capillaires susceptibles d'être endommagés par des particules de carbone. Un petit groupe de hamsters chinois normaux ou avec un diabète juvénile non-traité a été étudié. L'examen histologique suggère clairement la présence d'une pathologie capillaire chez les animaux diabétiques. Chez ces derniers, le rapport entre cellule endothéliale ( $E$ ) et périzyte intramural (IMP) est significativement élevé.

Erste Beobachtungen über das retinale Gefäßsystem des chinesischen Hamsters

Zusammenfassung. Verschiedene Methoden zur Untersuchung des Netzhautgefäßsystems chinesischer Hamster in vivo oder post mortem werden beschrieben. Es handelt sich um die Fundusphotographie, die Fluorescein-Angiographie und die Markierung beschädigter Capillaren mit Kohlepartikeln. Eine kleine Gruppe unbehandelter diabetischer und normaler chinesischer Hamster wurde untersucht. Histologisch waren die Netzhautcapillaren diabetischer Tiere verändert. Im Verhältnis zur Zahl der Endothelzellen waren die intramuralen Pericyten bei diabetischen Tieren deatlich vermindert.

Key-words: Diabetes mellitus, diabetic retinopathy, chinese hamster, fundus photography, fluorescein angiography, endothelial cells (E), intramural pericytes (IMP), E/IMP, retinal vasculature, dise, carbon particles, and retinal capillaries.
The purpose of this study was to apply some of the modern methods developed for the investigation of the human retina to the small eye of the chinese hamster. Retinal photographs and fluorescein angiograms were successfully completed and correlated with histopathologic studies. Experiments also included trypsindigested flat mounts [7] of the retinas from animals previously injected with carbon particles, in order to demonstrate possible leaks in the basement membrane of retinal capillaries. Labeling with carbon particles was previously described in the study of the mechanism of vascular leakage in inflammation $[8,9]$. Finally, the ratio of endothelial cells $(\mathrm{E})$ to intramural pericytes (IMP) was easily determined in trypsin-digested flat mounts.

The need for an experimental model of diabetic retinopathy cannot be overemphasized. Diabetes mellitus has become the major cause of blindness except for glaucoma and cataracts [11]. Retinal changes have been reported in spontaneous diabetic dogs and cats $[4,10]$, and in chemically induced canine diabetes [1] No changes were found in the alloxan-diabetic rat [3, 10]. The chinese hamster was selected since it develops diabetes spontaneously while control animals are available within the same strain. A large, well-established colony of animals is available, and retinal changes have been previously described in this species [12].

* This study was supported by National Eye Institute Retinal Clinical Research Grant EY-00341

\section{Material and Methods}

The retinal vasculature of twenty chinese hamsters was studied. There were eight males (four diabeties and four normals) and twelve females (six diabetics and six normals). The animals ranged in age from 12 to 32 months, and for each diabetic there was a control animal of the same age. The diabetics were all of the juvenile type and untreated. The fasting blood sugar in any diabetic was always greater than $250 \mathrm{mg} \%$ and the urinary glucose was always greater than $500 \mathrm{mg} /$ $24 \mathrm{~h}$. To study the ocular fundus with indirect ophthalmoscopy the animal was first anesthetized with an intraperitoneal injection $(0.11 \mathrm{ml} / 10 \mathrm{~g})$ of nembutal $(5$ $\mathrm{mg} / \mathrm{ml}$ ). The pupils were dilated with $10 \%$ neosynephrine and $1 \%$ cyclogyl. All the animals were studied in this manner.

Fundus Photography: After the animal was prepared as above, the posterior pole of the eye was photographed with the Zeiss ocular fundus camera. Other areas of the retina were photographed with the Kowa fundus camera.

Fluorescein Angiography: With the animal prepared as described, a vertical incision on the thigh, medially close to the abdomen was made and the femoral vein was exposed. A 27 -gauge needle on the end of a polyethylene tube attached to a tuberculin syringe ( $5 \%$ fluorescein) was placed in the femoral vein. While $0.03 \mathrm{ml}-0.05 \mathrm{ml}$ of fluorescein was quickly injected, 
rapid sequence photography of the posterior pole was performed with the Zeiss fundus camera.

Injection with carbon particles: The animal was prepared in the same manner used for fluorescein injection. A colloidal suspension of carbon particles (average particle size of $200 \mathrm{~A}$ ) was injected $[8,9]$ into the femoral vein $(0.025 \mathrm{ml} / 25 \mathrm{~g}$ body weight). Two hours later the animal was killed and the eyes were taken for histologic study.

Histologic techniques: While the animal was deeply anesthetized, both globes were enucleated and placed in formalin solution for at least $24 \mathrm{~h}$. The animal with indirect ophthalmoscopy. There was much variability in the clinical appearance of the retinal vasculature of the normal chinese hamster. In most animals the vessels radiate in relatively straight lines from the dise (Fig. 1). In some animals the vessels were more tortuous. The number of main vessel trunks varied from eight to twelve. The arteries and veins alternated and were usually equal distance from one another. Oceasionally an artery and vein could be seen running side by side.

The disc was seen to be an elevated, pigmented, conical-shaped structure. There was always what ap-

Fig. 1. Fundus photograph showing the dark pigmented disc in the center with the large retinal vessels radiating out directly from the disc. All the retinal vessels are filled with fluorescein and appear white

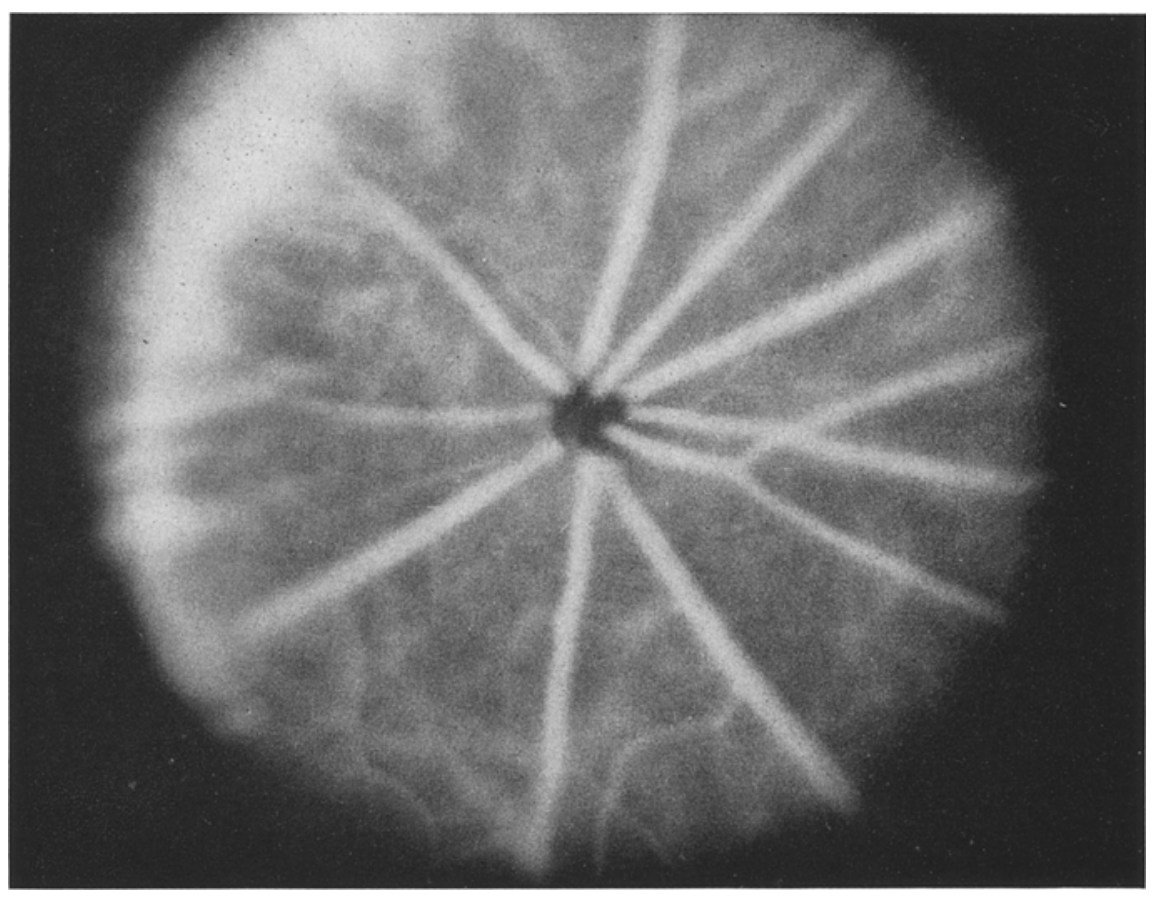

was then euthanized. The retina from one globe was then used to make a trypsin-digested flat mount [7] stained with PAS and hematoxylin. The other eye of the pair was embedded in paraffin, and sections (cut at $6 \mu$ ) were made in the anterior-posterior plane. These were stained with $\mathrm{H} \& \mathrm{E}$ or PAS and hematoxylin.

Determination of $E / I M P$ : The ratio of endothelial cells $(\mathrm{E})$ to intramural pericytes (E/IMP) was derived from cell counts at $430 \times$ magnification. Four separa te counts were made for each retina, two at the posterior pole and two in the mid-periphery. All the endothelial cells and all the intramural pericytes of capillaries were counted in each field. The E/TMP for each animal was estimated by averaging the four counts.

\section{Results}

Of the twenty animals studied, six had cataracts which made photography impossible. In most of these, the retinal vascular patterns could still be visualized peared to be an artery running around its distal end. The arteries left the disc distally, while the veins seemed to enter the disc at its base.

Histologically, as the vessels leave the dise they are elevated and then rapidly slope down into the nerve fibre layer of the retina (Fig. 2). The larger main vessel trunks range in diameter from $50 \mu$ to $70 \mu$, the veins being slightly larger than their companion arteries. These main trunks branch into smaller ressels ranging in diameter from $15 \mu$ to $40 \mu$. Interwoven between these vessels is a dense network of capillaries $7 \mu$ to $10 \mu$ in diameter, and these vessels appear to comprise the bulk of the retinal circulation. The trypsin-digested flat mounts show that morphologically, the retinal vessels of the chinese hamster are quite similar in every respect to the human preparations (Fig. 3). On crosssection the larger vessels are seen in the nerve fibre layer and ganglion cell layer, while the capillary network weaves through the inner plexiform, inner nuclear, and just into the outer plexiform layer of the retina (Figs. 4 and 5). 


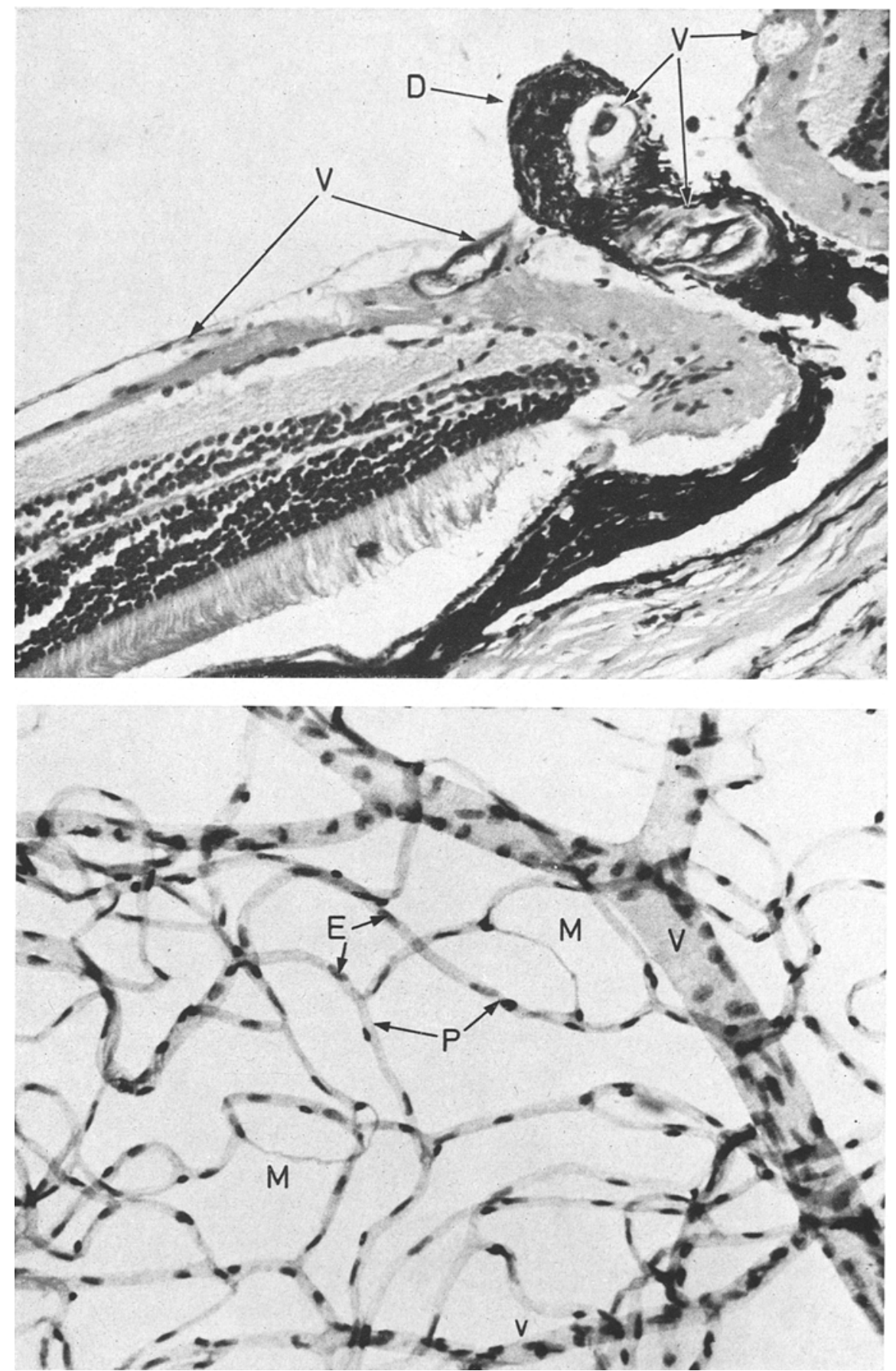

Fig. 2. Cross section of the retina of a normal chinese hamster cut through the disc, showing the elevated, pigmented structure of the disc (D), with the larger retinal vessels (V) coming out from this and going down into the nerve fiber layer of the retina
Fig. 3. Trypsin digested, flat retinal preparation of the normal chinese hamster showing endothelial cells $(\mathrm{E})$, intramural pericytes $(\mathrm{P})$, mesodermic tracts $(\mathrm{M})$, and a retinal vein (V) with smaller venules $(v)$
The capillary network showed the same morphological aspect in all areas of the retina. The meshwork was more dense (i.e., more capillaries/area) in the posterior pole than in the periphery. An area suggestive of a macula could not be found in either the flat preparations or on funduscopic examination.

In mounting the trypsin-digested flat retinal preparations the normal three dimensional vascular pattern is distorted by placing all the vessels in a two dimensional plane. Some of the small capillaries become folded on themselves causing a constriction at each fold. There are always two constrictions with a normal diameter vessel between which can easily be mistaken for a fusiform-shaped aneurysm.

In the diabetic animals studied the clinical appearance was the same. There were no hemorrhages or aneurysms, and what appeared as exudates or retinal edema turned out to be material in the corpus vitreum. 
Fig. 4. Cross section of the retina of a normal chinese hamster killed immediately after carbon injection, show ing the retinal capillaries filled with carbon and the various lavers of the retina: Internal limiting membrane (I), nerve fiber layer (N), ganglion cell layer $(G)$, inner plexiform layer (IP), inner nuclear layer (IN), outer plexiform layer (OP), outer nuclear layer (ON), photoreceptor cells (R), Bruch's membrane (B), capillaries filled with carbon (C), pigment epithelium (P)
Fig. 5. Cross section of the retina of a normal chinese hamster showing the endothelial cells $(\mathbf{E})$ of the retinal capillaries in the inner plexiform and inner nuclear layers
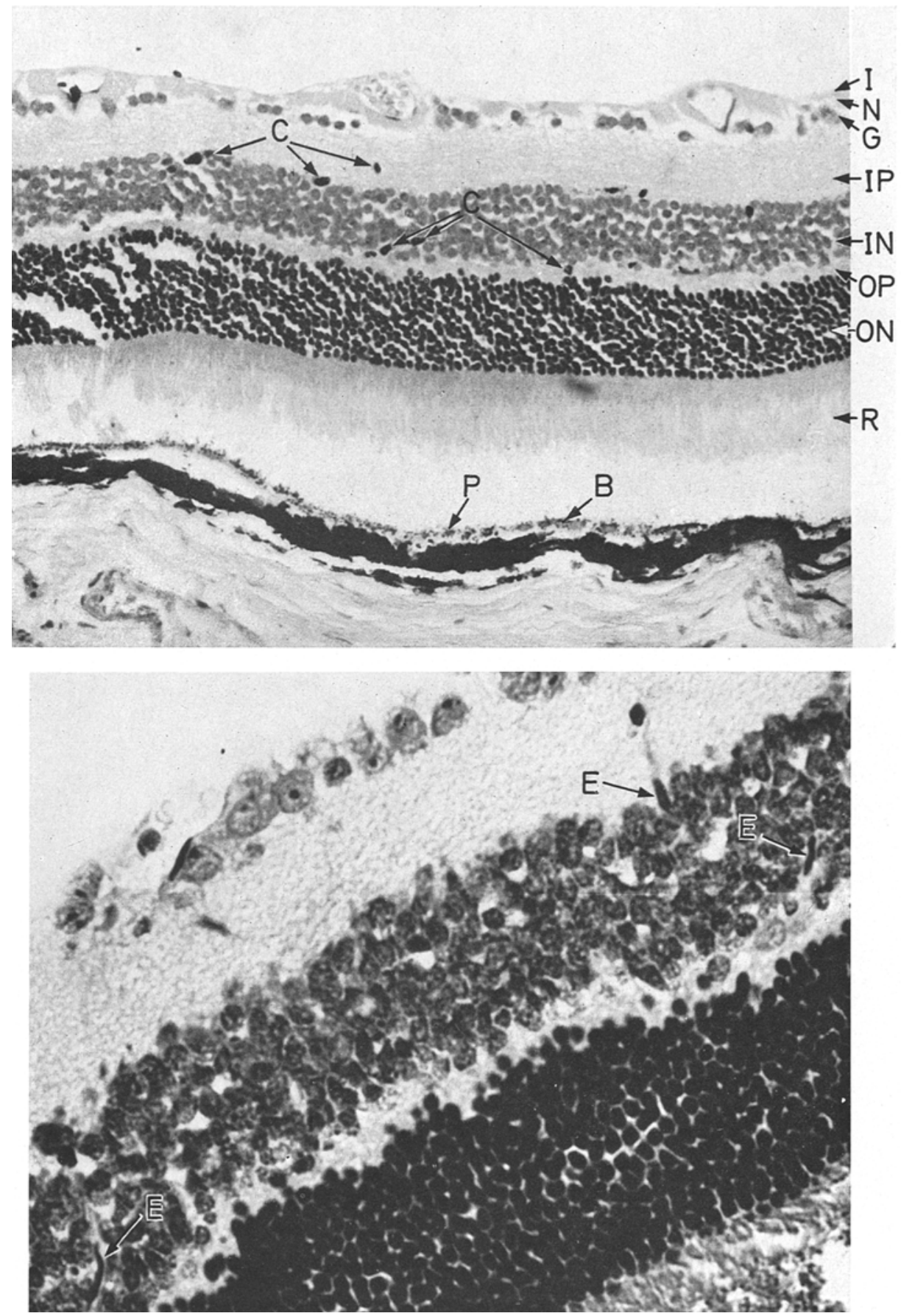

Upon histological examination, the diabetic animals showed no aneurysms other than the artefacts previously described. In four of the diabetics there was an occasional length of capillary with no endothelial cells and no intramural pericytes (Fig. 6). These vessels were usually seen near a collecting venule. These could very well be artefacts.

In four animals studied by injection of carbon particles, the two diabetics showed carbon in some of the small capillaries (Fig. 7). The carbon labeled vessels were mostly found on the venous side of the capillary bed. There were no carbon particles seen in the retinal vasculature of the normal animal two hours after injection.

The ratio E/IMP was significantly elevated in the diabetic animals as compared with the normal control group (Table 1). There was no significant correlation of the E/IMP-ratio to the age of the animal or to the 

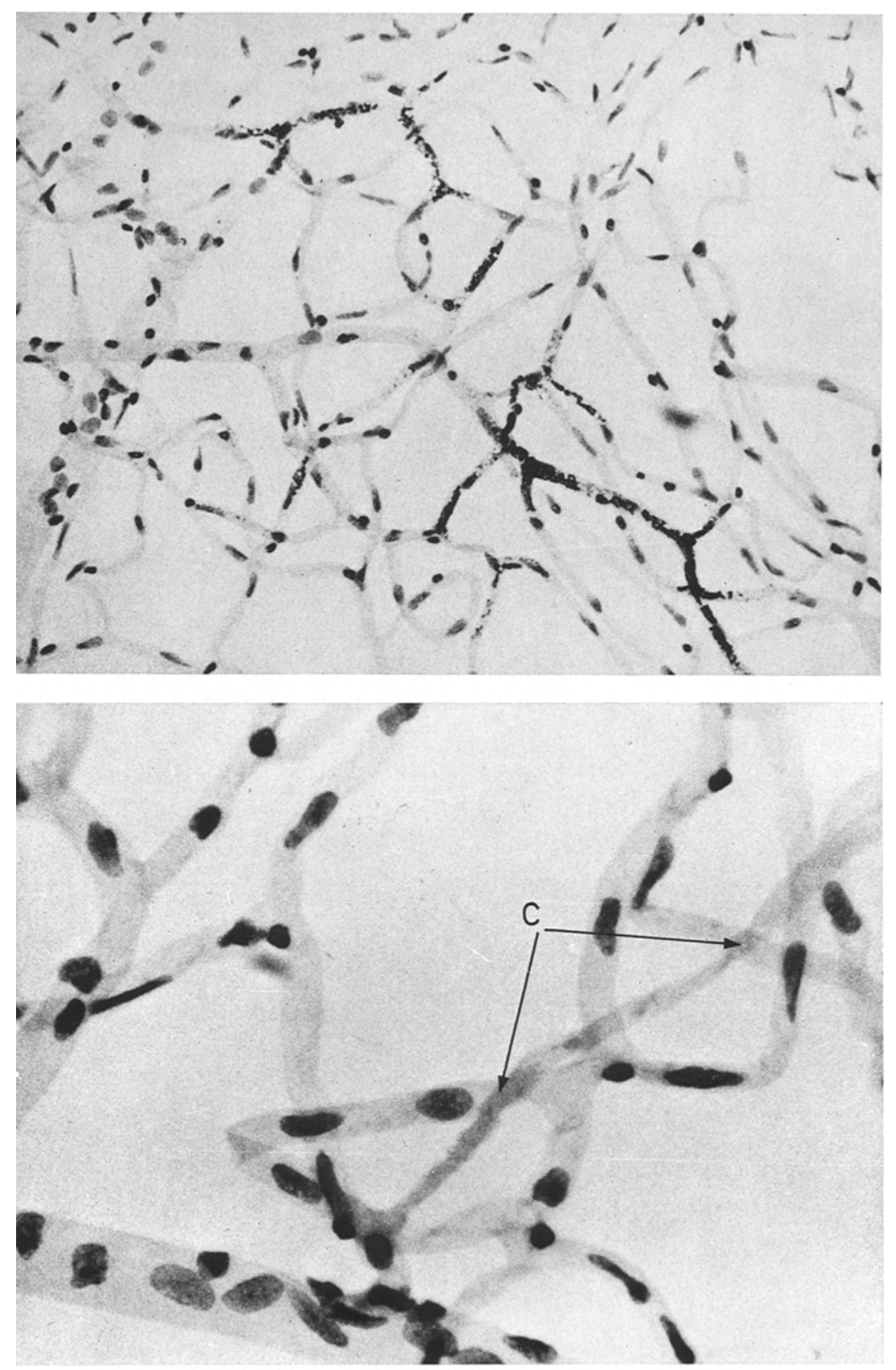

Fig. 6. Trypsin digested, flat retinal preparation of a diabetic chinese hamster (No. F $1-5$ ) showing a retinal capillary (C) with no endothelial cells and no intramural pericytes
Fig. 7. Trypsin digested, flat retinal preparation of a diabetic chinese hamster (No.XA 2-15), showing retinal capillaries labeled with carbon particles duration of diabetes or ketosis. It is interesting that the E/IMP was greater in the female diabetics than in the male diabetics, whereas no significant difference in this respect was found between the normal males to the normal females (Table 1 ).

In two animals fluorescein angiography was successfully carried out, and there was no apparent difference between the normal and the diabetic animal. With the fluorescein technique one could differentiate the
Table 1. Ratio of endothelial cells to intramural pericytes (E/IMP) of the retinal capillaries of chinese hamsters

$95 \%$ con-

Classification Sex No. Mean \pm S.D. fidence

interval

\begin{tabular}{llrll}
\hline Diabetic & Female & $\mathbf{6}$ & $\mathbf{2 . 6 6 \pm 0 . 2 1}$ & $\mathbf{2 . 4 4}-\mathbf{2 . 8 8}$ \\
Diabetic & Male & 4 & $2.34 \pm 0.20$ & $2.03-2.75$ \\
Normal & M \& F & $\mathbf{1 0}$ & $\mathbf{2 . 0 3} \pm 0.09$ & $1.97-2.00$ \\
\hline
\end{tabular}


arteriole filling phase from the venous collecting phase. Smaller vessels which were not seen by indirect ophthalmoscopy were seen with fluorescein angiography (Fig. 1).

\section{Discussion}

Fundus photography and fluorescein angiography are techniques which can be used to study the retinal vasculature of the chinese hamster. With these techniques a permanent record of the clinical picture can be made. Fluorescein angiography demonstrates details not visible by other clinical means. There is general agreement that histologically, in the human diabetic, the earlier changes consist in a loss of intramural pericytes and a dysfunction of the basemant membrane of the retinal capillaries $[1,2,13,14]$. In the diabetic chinese hamster, no definite pathologic changes were observed which could be considered to be similar to those in human diabetes either clinically or by histologic studies. The occasional capillaries seen without cells and the fact that some of the capillaries do become labeled with carbon particles is suggestive of pathologic changes in the diabetic animals. The significant elevation of the E/IMP-ratio in the diabetic animals serves as more concrete evidence of the presence of pathology. It is felt that the results of this work indicate that further studies of the retinal vasculature of the chinese hamster should be undertaken.

Acknowledgements: The authors are indebted to Dr. William C. Frayer for the generous use of his laboratory facilities and for his advice on various techniques, and to Dr. Thomas Behrendt for the use of the Zeiss eamera and other photographic facilities. They are particularly in debted to Dr. 'Thomas D. Duane for his constant encouragement and support for this work. They wish to thank Drs. P. Robb McDonald and Lov K. Sarin for the use of their Kowa camera, and to acknowledge the skillful technical assistance of the technician staff from the pathology and photographic sections of the Department of Ophthalmology.

\section{References}

1. Bloodworth, J.: Fine structure of retina in human and canine diabetes mellitus. In: Kimura, S.J., Caygill,
W.M. (eds.): Vascular complications of diabetes mellitus, pp. $73-98$. St. Louis: The C.V. Mosby Co. 1967.

2. Cogan, D.G., Toussant, D., Kuwabara, T.: Retinal vascular patterns: IV. Diabetic retinopathy. Arch. ophthal. 66, 366-378 (1961).

3. Futterman, S., Sturtevant, R., Kupfer, C.: Effect of alloxan diabetes on the fatty acid composition of the retina. Invest. ophthal. 8, 542-544 (1969).

4. Gepts, W., Toussaint, D.: Spontaneous diabetes in dogs and cats. Diabetologia 3, 249-265 (1967).

5. Gerritsen, G.C., Dulin, W.E.: Characterization of diabetes in the Chinese hamster. Diabetologia 3, 74-84 (1967)

6. Gundersen, K., Yerganian, G., Lin, B.J., Gagnon, H., Bell, F., McRae, W., Onsberg, T.: Diabetes in the Chinese hamster. Diabetologia 3, 85-91 (1967).

7. Kuwabara, T., Cogan, D.G.: Studies of retinal vascular patterns: I. Normal architecture. Arch. ophthal. 64, 904-911 (1960).

8. Majno, G., Palade, G.E.: Studies on inflammation: I. The effect of histamine and serotonin on vascular permeability: An electron microscopic study. J. biophys. biochem. Cytol. 11, 571-605 (1961).

9. - - Schoefl, G.I. : Studies on Inflammation: II. The site of action of histamine and seratonin along the vascular tree: A topographic study. J. biophys. biochem. Cytol. 11, 607-626 (1961).

10. Meier, H.: Diabetes mellitus in animals. A review. Diabetes 9, 485-489 (1960).

11. Newell, F.W.: The problem of diabetic retinopathy. In : Kimura, S.J., Caygill, W.M. (eds.): Vascula rcomplications of diabetes mellitus pp. $35-39$. St. Louis: C.V. Mosby Co. 1967.

12. Sirek, O.V., Sirek, A.: The colony of Chinese hamsters of the C.H. Best Institute. Diabetologia 3, 6573 (1967).

13. Speiser, P., Gittelsohn, A.M., Patz, A.: Studies on diabetic retinopathy: III. Influence of diabetes on intramural pericytes. Arch. ophthal. 80, 332-337 (1968).

14. Yanoff, M.: Ocular pathology of diabetes mellitus. Amer. J. Ophthal. 67, $21-38$ (1969).

Jay L. Federman, M.D.

Department of Ophthalmology

Jefferson Medical College of

Thomas Jefferson University

1025 Walnut Street

Philadelphia, Pa. 19107, USA

Colour prints may be obtained upon request. 